\title{
Prediction of the stacking fault energy in austenitic stainless steels using an artificial neural network
}

\author{
A. Román, B. Campillo, H. Martínez, O. Flores
}

\begin{abstract}
Stacking fault energy (SFE) is an important parameter to be considered in the design of austenitic stainless steels (SS) due to its influence on magnetic susceptibility, atomic order changes and intergranular corrosion resistance. An extensive review of specialized literature was examined in order to understand the different methods that have been developed for the calculation of SFE. Characterization by transmission electron microscopy (TEM), linear expressions from data processing and first-principles quantum mechanics approximations are some techniques that have been used for this objective. In the present work a feed forward backpropagation artificial neural network (ANN) was developed to predict the SFE within given specific ranges of chemical compositions of austenitic SS. The experimental data were extracted and analyzed from a research work reported by Yonezawa et al [1], for three different heat treatment conditions. The model predicts SFE values with a correlation coefficient of 0.99 , which reduce the error when is compared with other works in the literature.
\end{abstract}

Index Terms - Neural network, Stacking fault energy, Austenitic stainless steel.

\section{INTRODUCTION}

The SFE is an important physical parameter for the design and characterization of properties in austenitic SS. Hardness, intergranular corrosion resistance and magnetic susceptibility are some properties that are affected in austenitic SS [2]-[5]. Usually SFE has been related only to the chemical composition; however the heat treatment and manufacturing process of the materials are also important issues. These processes may induce large deformations, causing atomic rearrangement; which generates new phases, modifying magnetic susceptibility and intergranular corrosion [2]-[10]. In the last 60 years, several works have been carried out with different techniques to determinate the SFE, among them are characterization by transmission electron microscopy (TEM) [1], [11]-[17]; X-ray diffraction (XRD) [18-21]; neutron diffraction [16], [22]. In the other hand, it has been developed expressions by linear multivariables analysis of experimental data [1], [12], [14], [23]-[26], and also computational thermodynamics and quantum mechanics first-principles simulations [1], [17], [27]-[31]. Recently, Arpan Das [32] developed a model of a Bayesian neural network for the calculation of SFE. The investigation demonstrated that the predictions were reasonable in the context of metallurgical principles and it

Román Alfonso, Universidad Autónoma del Estado de Morelos/ Centro de Investigación en Ingeniería y Ciencias Aplicadas, Cuernavaca, Morelos.

Campillo Bernardo, Universidad Nacional Autónoma de México/ Facultad de Química, Ciudad de México.

Martínez Horacio, Universidad Nacional Autónoma de México/ Instituto de Ciencias Físicas, Cuernavaca, Morelos

Flores Osvaldo, Universidad Nacional Autónoma de México/ Instituto de Ciencias Físicas, Cuernavaca, Morelos. also compared with other issued works. Yonezawa et al. [1] elaborated several austenitic SS, considering three heat treatments and its manufacture process. They calculated the SFE by TEM characterization of the three heat treatments, which were: solution heat treatment-water cooling (SHTWC), solution heat treatment-furnace cooling (SHTFC), and aging (AGG). The experimental SFE values obtained were compared with the theoretical ones. The evaluation was performed by first-principles approach based on the density functional theory (DFT) [1], and proposed a highly efficient multivariable linear model. In the present work we developed a feed forward back propagation ANN for the prediction and comparison of SFE as a function of the chemical composition-dependence of Yonezawa's work. The ANN was specifically designed and constrained for 33 Mo content austenitic SS alloys, considering only the SFE data reported for the three heat treatments [1]. Also the results were compared with other authors [1], [14], [24]-[26].

\section{METHOD}

Artificial neural networks (ANNs) have been widely applied in different fields of science and technology due to their efficiency in representing non-linear processes and its accuracy predictions. Many types of ANN's models have been proposed and evaluated in different applications, such as the prediction of mechanical properties, corrosive resistance, particle sizes, and even applied in Large Hadron Collider (LHC) [32]-[38]. In this work the proposed ANN consist of one hidden layer and 12 neurons. They were selected by manual iterative method until a minimum error was achieved $(0.01 \%)$. The minimum squared error $(M S E)$ is the training error of the model, defined as:

$$
\text { MSE }=\frac{1}{N} \sum_{i=1}^{N}\left(Y_{i}-S_{i}\right)^{2}
$$

Where $N$ is the training number, $S_{i}$ and $Y_{i}$ are outputs of the $i_{\text {th }}$ output neuron, wherBe $S_{i}$ and $Y_{i}$ are the output of the experimental data and the approximated value, respectively [35]. To obtain a faster convergence, the gradient descent method was used and the Levenberg-Marquardt algorithm was selected for this purpose [39]-[41]. Figure 1 shows the architecture of the ANN. The input layer corresponds to the 33 chemical compositions of the alloys in wt $\%$. A hidden layer composed of 12 neurons is used and finally the output layer corresponds to $99 \mathrm{SFE}$ calculations for the three different heat treatments (SHTWC, SHTFC and AGG). The activation function $(f(x))$ used in all the neurons is shown in Figure 2, which it is used and proposed in cases with soft signal variations [42]. The mathematical expression and the input values $(x)$ are shown in equations (2) and (3) respectively. The data was normalized from 0 to 1 . 


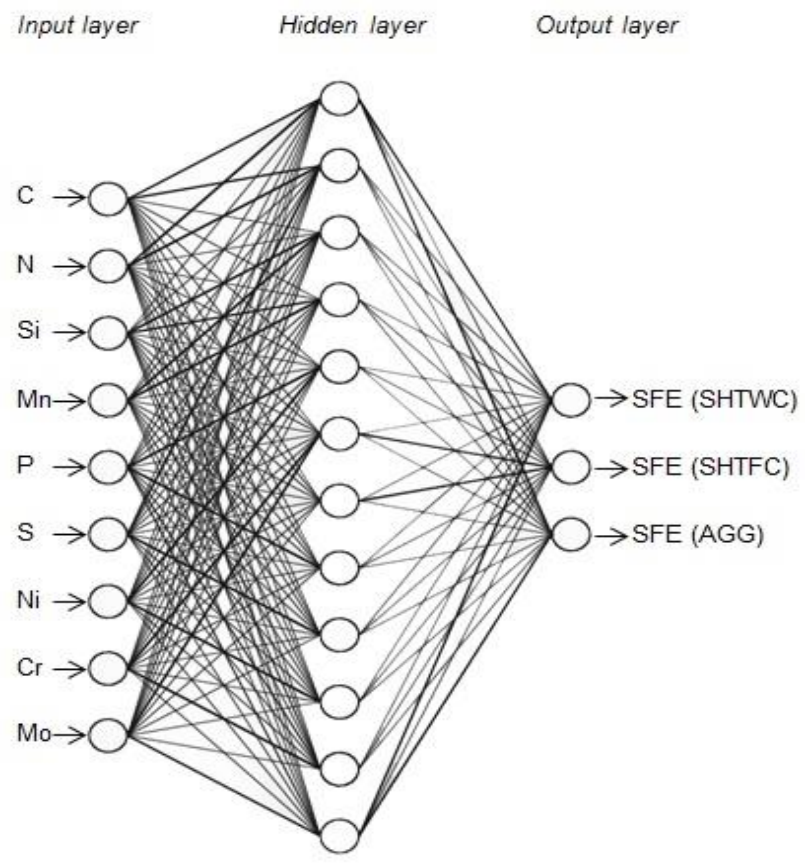

Fig. 1. ANN's architecture.

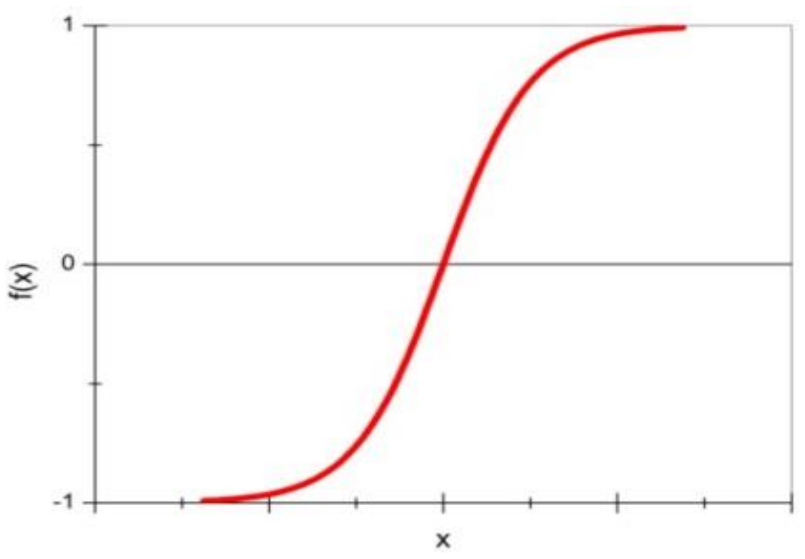

Fig. 2. Hyperbolic tangent activation function.

$f(x)=\frac{2}{1+\exp ^{-2 x}}-1$

Where:

$x=\sum_{i=1}^{n} X_{i} W_{i}+\theta$

and $X i$ are input values, $W i$ are weights and $\theta$ are the biases.

\section{RESULTS AND DISCUSSION}

The selected data from Yonezawa's research that corresponds to the measurements performed by TEM and their corresponding SFE calculations for three types of heat treatments were used. In general, there is a lack of clear information in the literature reviewed regarding the thermomechanical process and experimental characterization. In order to avoid inconsistencies due to the later statement; the only data considered were the 99 contributions of Yonezawa's work. We consider that the prediction range obtained by the values calculated [1] are sufficient for an optimal performance of our model. In order to create the ANN, the selected data were stochastically divided as follows: 63, 12 and 12 for training, validation and testing respectively. To complete the ANN development, the 12 last data were simulated for the final validation. The weights and biases corresponding to the proposed ANN are additional material to the present paper, ensuring its possible re-creation of the model for use in predicting SFE. The performance obtained has a correlation coefficient of 0.99 . The acquired prediction accuracy allows us to perform SFE calculations for three types of heat treatments within the given chemical composition ranges, which are shown in Table 1 .

Table 1: Chemical composition ranges of the ANN.

\begin{tabular}{|l|l|l|}
\hline $\begin{array}{l}\text { Chemical composition } \\
\text { (wt \%) }\end{array}$ & Maximum & Minimum \\
\hline Carbon & 0.075 & 0.0006 \\
\hline Nitrogen & 0.107 & 0.001 \\
\hline Silicon & 1.82 & 0.01 \\
\hline Manganese & 3.95 & 0.01 \\
\hline Phosphorus & 0.03 & 0.004 \\
\hline Sulfur & 0.0024 & 0.0002 \\
\hline Nickel & 19.85 & 10.8 \\
\hline Chromium & 24.11 & 13.09 \\
\hline Molybdenum & 2.7 & 0.04 \\
\hline
\end{tabular}

A. Predicted and characterized Values of SFE for SHTWC, SHTFC and AGG heat treatments.

The effect of heat treatment on the design of austenitic SS is an important factor in the process of these alloys. Although, it is necessary to bring about a proposal to predict SFE based on the heat treatment and its chemical composition. We selected the ANN model in order to simulate SFE values. Figures $3 \mathrm{a}, 3 \mathrm{~b}$ and $3 \mathrm{c}$ depict the comparison of both predicted and characterized values for the three heat treatment conditions. The calculated linear regression coefficient between the data is $R^{2}=0.99$, validating high efficiency for the prediction of SFE by the present proposed ANN. Figure 3d shows the whole comparison between all the values among the heat treatments.

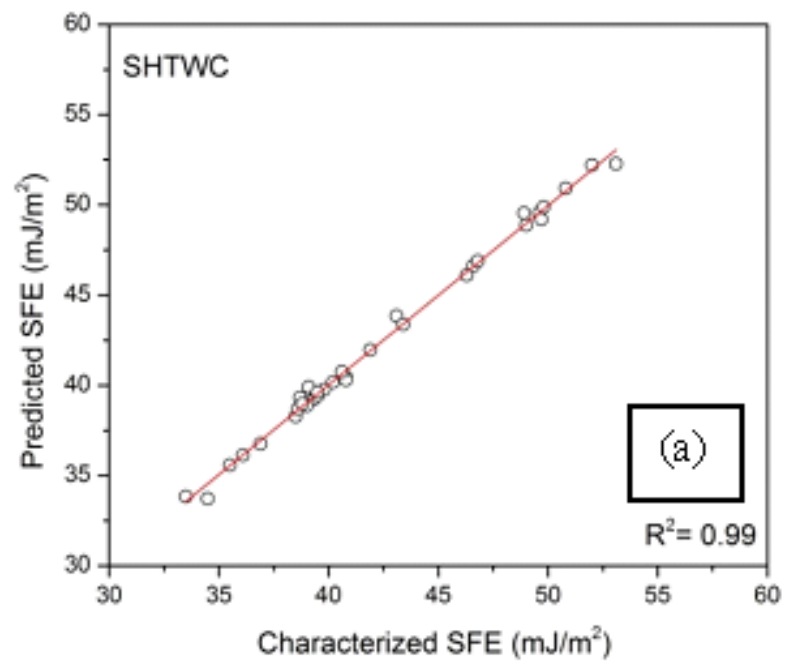



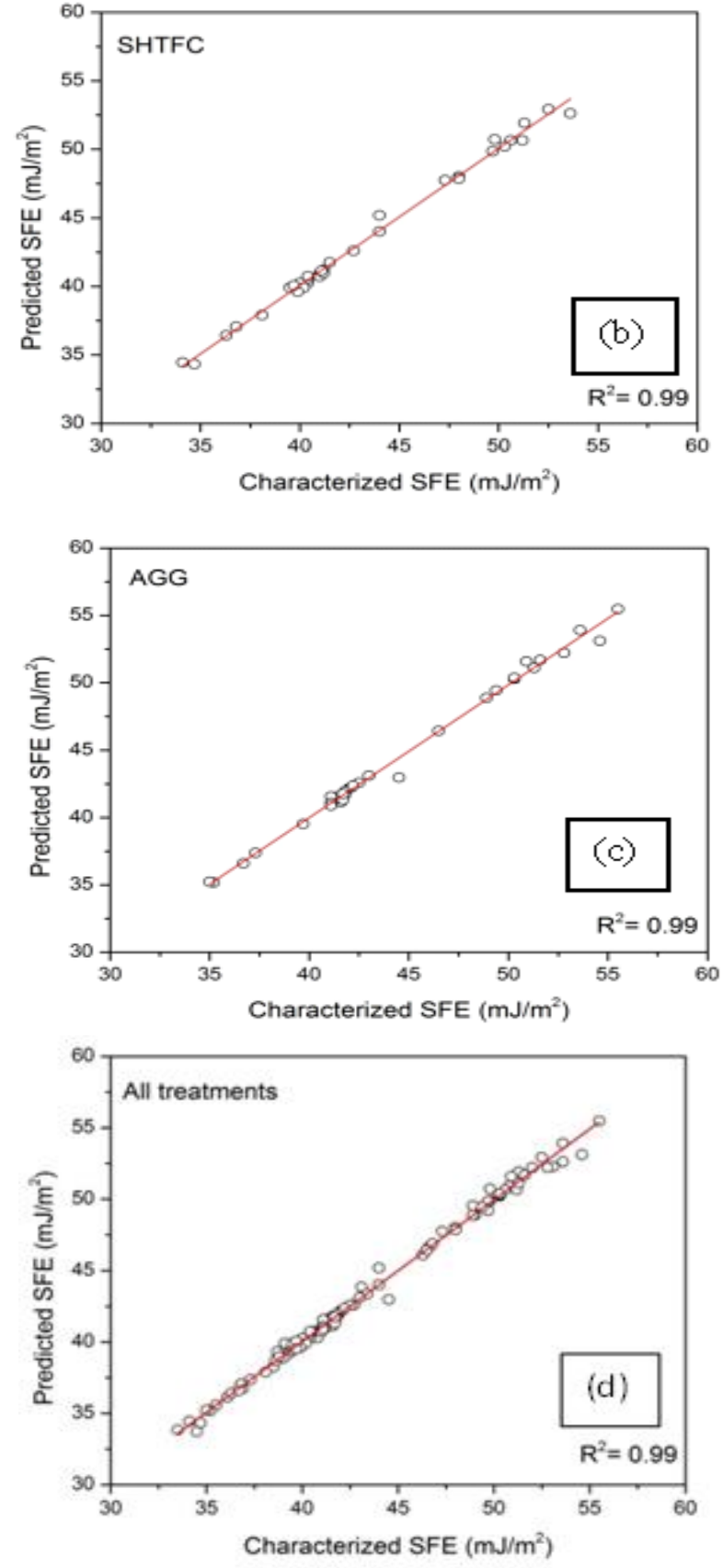

Fig. 3. (a-d) Comparison between the values both characterized and predicted of SFE for the three heat treatments.

Employing the same selected characterized chemical composition data base from Yonezawa's work [1] as mentioned previously, SFE values were evaluated. The later was performed using the models reported by [1], [14], [24]-[26] and the proposed ANN model from this work. It is important to point out that these calculations correspond only for the austenitic SS in the water cooling condition (SHTWC). In figure $4 \mathrm{a}$ it is shown the predicted SFE values for all the compared models. To observe the trend of the values, a scale adjustment was done as shown in figure $4 \mathrm{~b}$. It can be observed that many of the data are even out of scale due to the difference in magnitude presented in the SFE calculations. The argument is that the models considered are usually designed only based on chemical composition and the influence of each element that has been analyzed and compiled in several previous works [1], [32].
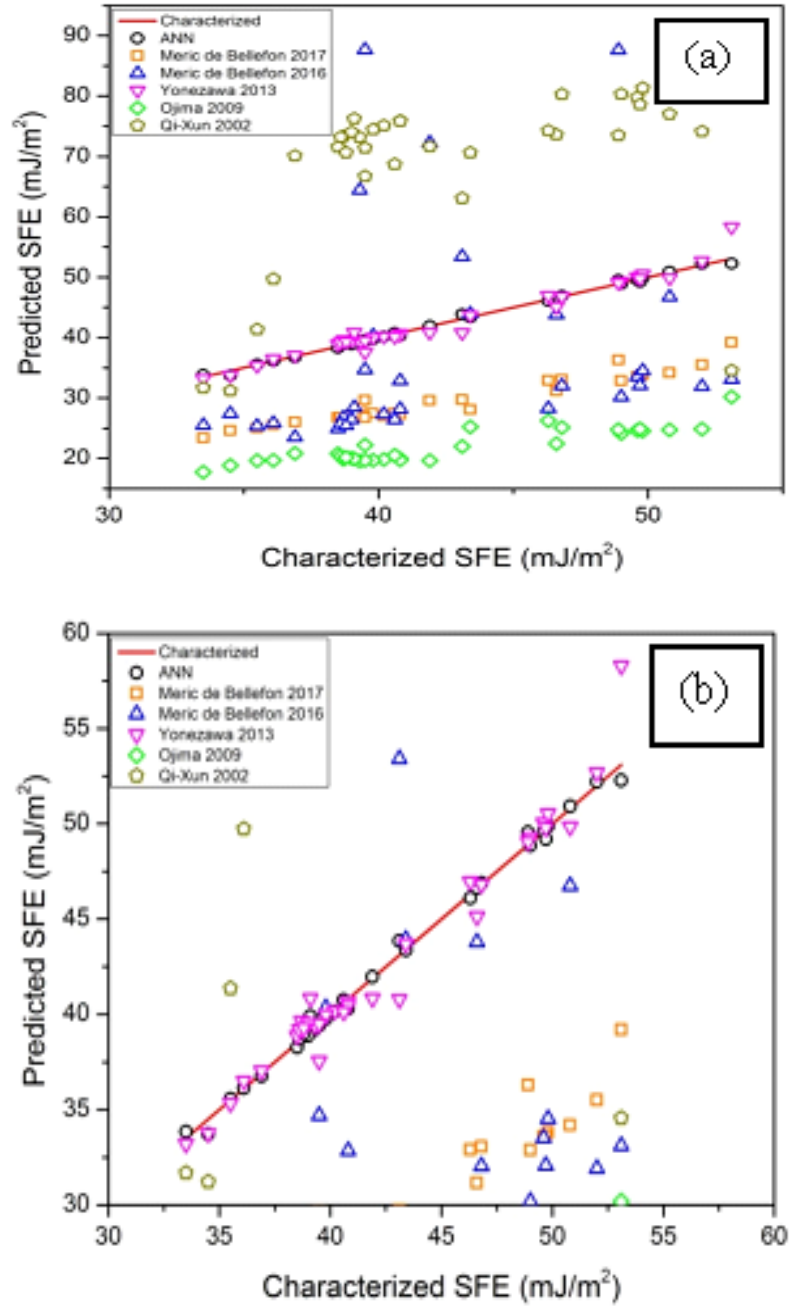

Fig. 4. (a) Comparison between the values of SFE characterized and predicted for the SHTWC condition. (b) Adjusted figure from $4 \mathrm{a}$.

The heat treatment and plastic deformation generally modify the crystal lattice because dislocation mechanism related to the precipitation of chromium carbide, increasing the SFE [2]-[10]. Hence the models just developed as function of the chemical composition are not able to make an efficiency prediction.

\section{B. The effect of heat treatment and chemical elements contents on SFE values.}

Using the ANN, the effect of each alloying element on austenitic stainless steels was studied. The minimum prediction value of the ANN was taken for each element up to the maximum value, increasing only one element (leaving the other elements constant), thus obtaining its impact on the SFE for the three heat treatments.

\section{Effect of Carbon on SFE}

Figure 5a shows the behavior of the SFE as a function of the increase in carbon content. For SHTWC the SFE decreases at low concentrations and increases at high carbon concentrations. On the other hand in SHTFC and AGG it is observed that at low concentrations the SFE decreases but on the contrary it remains more stable with higher concentrations of carbon. Petrov and Yakubtsov [43] 
obtained similar results with theoretical calculations, obtained the decrease of SFE with low carbon contents and high with its increase.

\section{Effect of Nitrogen on SFE}

The effect of nitrogen on the SFE for the three heat treatments is shown in Figure 5b. The ANN predicts a descending behavior of SFE in all three cases, depending on the increase in nitrogen content. These results have been obtained by several authors experimentally. The main problem is that for this type of steels, the nitrogen content is limited, which does not allow analyzing higher concentrations. However, other researchers have found contrary results for the effect of nitrogen on SFE [32].

\section{Effect of Silicon on SFE}

According to Schramm and Reed [23] the increase in silicon content decreases the SFE. It also retains the transformation sequence (FCC to HCP) during cooling and deformation. This behavior is shown in Figure 5c. The ANN predicted the same behavior reported previously [1], [23], [32].

\section{Effect of Manganese on SFE}

The increase in Mn content generates increases in SFE. It is observed in figure $5 \mathrm{~d}$ for the three heat treatments that its impact is moderately high. In several investigations, the same behavior has been reported with respect to this alloy element [1], [19], [23], [32].

\section{Effect of Phosphorus and Sulfur on SFE}

Generally in steels, $\mathrm{S}$ and $\mathrm{P}$ are added to improve their machinability (contents greater than $0.1 \%$ ). Since corrosion resistance decreases, in austenitic stainless steels it is convenient to keep the contents as low as possible. Figures 5e and $5 f$ show the effect of both elements on the SFE. Measuring its effect is complicated, so there is a lack of information in the literature which can show results of the expected effect on SFE. Therefore, the behaviors observed in the aforementioned figures are generated by the prediction of the ANN, which in order to demonstrate its performance validation is needed additional experimental characterization.

\section{Effect of Nickel on SFE}

Figure 6a shows the effect of $\mathrm{Ni}$ on the SFE. There is a large increase in SFE with respect to the increase in $\mathrm{Ni}$ content. The increase is due to the fact that the Ni influences the cross slip dislocation, generating more defects in the crystal lattice [44]. In the SHTWC and AGG treatments similar behaviors are presented except for the defects generated by the AGG (increase in energy). However, the SHTFC shows drastic energy increases based on the content of Nickel. The reason can be attributed to the excess content in $\mathrm{Ni}$ and the lack of other alloying elements. The dislocations are greater, as a result of the slow cooling they get enough time to generate. This does not occur in the other two treatments, due to water cooling [32].

\section{Effect of Chromium on SFE}

Figure $6 \mathrm{~b}$ shows the impact of $\mathrm{Cr}$ on SFE. It has been reported that $\mathrm{Cr}$ does not significantly affect the SFE [1], [32], [45], [46]. Therefore, in high chromium contents but low carbon contents, not much defects (precipitation) are expected, hence the energy will not depend on the formation of these chromium carbides. The difference found in the three heat treatments can be explained by the phase relaxation time. Thus the SHTFC contains less energy for its prolonged cooling time, while the SHTWC conserves the residual stresses that can be formed by water cooling. The AGG presents less energy by the treatment at $650^{\circ} \mathrm{C}$ for two hours; this could dissipate a small amount of residual stress present, obtaining a small decrease in SFE.

\section{Effect of Molybdenum on SFE}

The Mo in austenitic stainless steels is added to improve the corrosion resistance of the material. The main characteristic of the addition of the Mo that has been found is the reduction of mobility of dislocations [32], [47]. The SFE is increased as a function of the increase of the Mo content. Figure 6c shows this behavior for the three thermal treatments. And as mentioned, the increase in energy between the treatments will depend on the type of element being studied and its effect generated by the heat treatment.
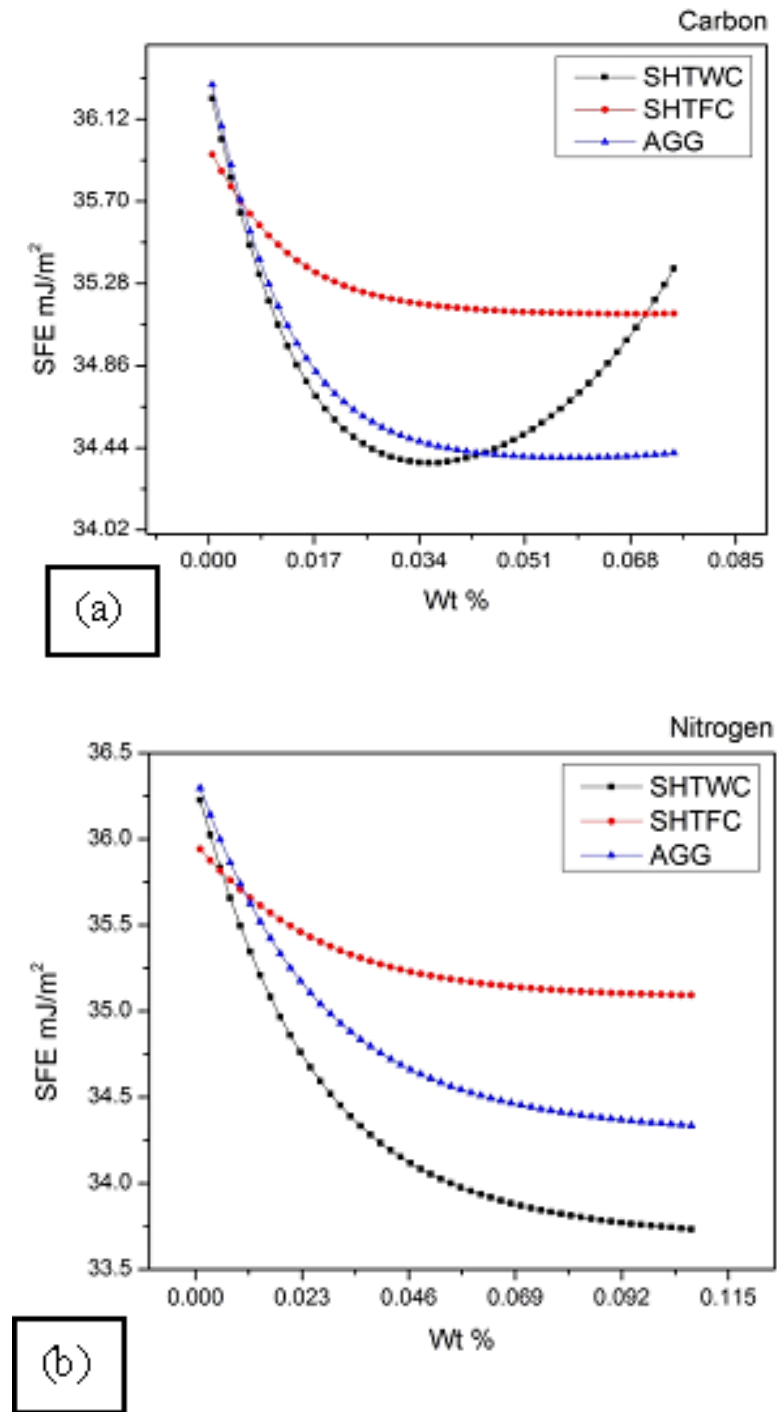

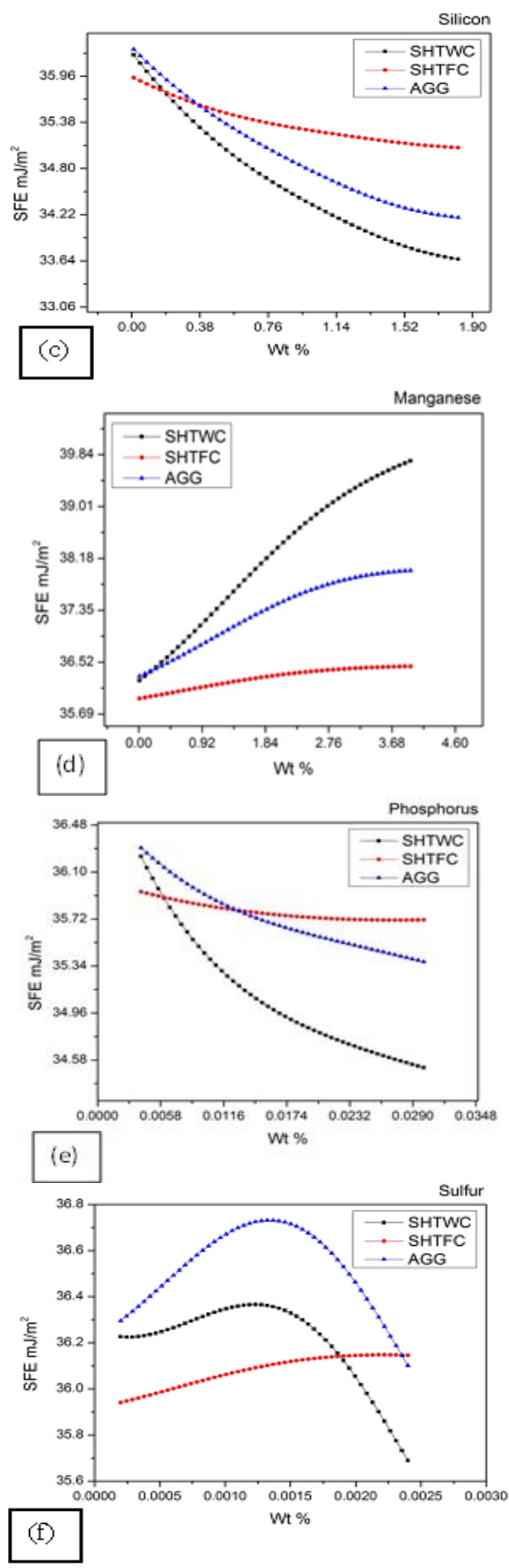

Fig. 5. Effect of alloying elements and heat treatments on the SFE. (a) Carbon. b) Nitrogen. c) Silicon. d) Manganese. e) Phosphorus. f) Sulfur.
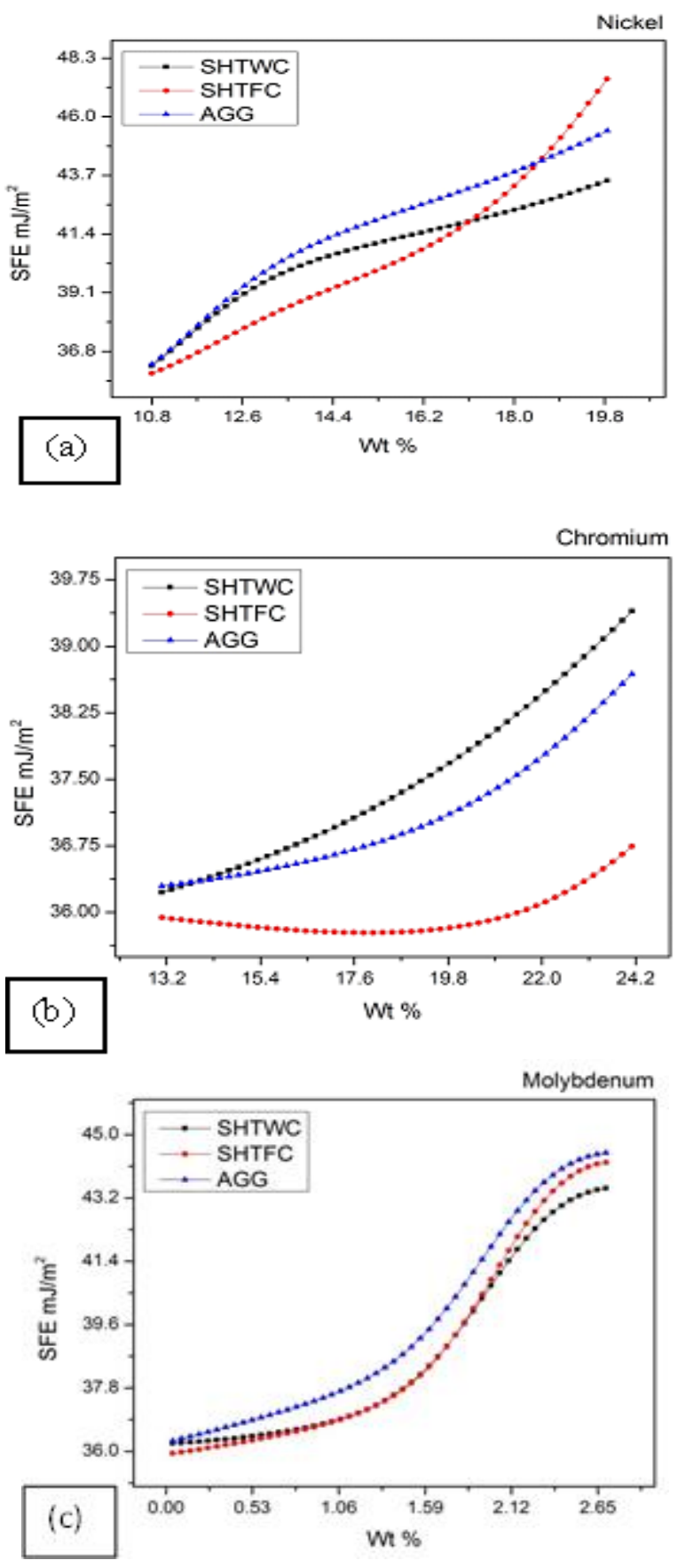

Fig. 6. Effect of alloying elements and heat treatments on the SFE. (a) Nickel. b) Chromium. c) Molybdenum.

Figures $7 \mathrm{a}, 7 \mathrm{~b}$ and $7 \mathrm{c}$ show the behavior of all the elements that were previously explained. It is observed that for the SHTFC the effect of the elements is less shocking, this could be generated due to the stability of the austenitic phase, since, when cooling slowly there are no residual stresses, obtaining an atomic order with more time to reach its stability. On the other hand the increase in its energy can be generated by cross slip dislocation, generating more defects in the crystal lattice that could be created during slow cooling in the furnace. Regarding SHTWC and AGG are similar behaviors, but the main difference is the generation of precipitates in the AGG, evident in grain boundaries [1]. These generate more energy because they are defects present in the crystal lattice. All the effects of the alloy elements on the SFE were similar to those reported by several authors [1], [19], [23], [32], [43], [44]-[47]. 

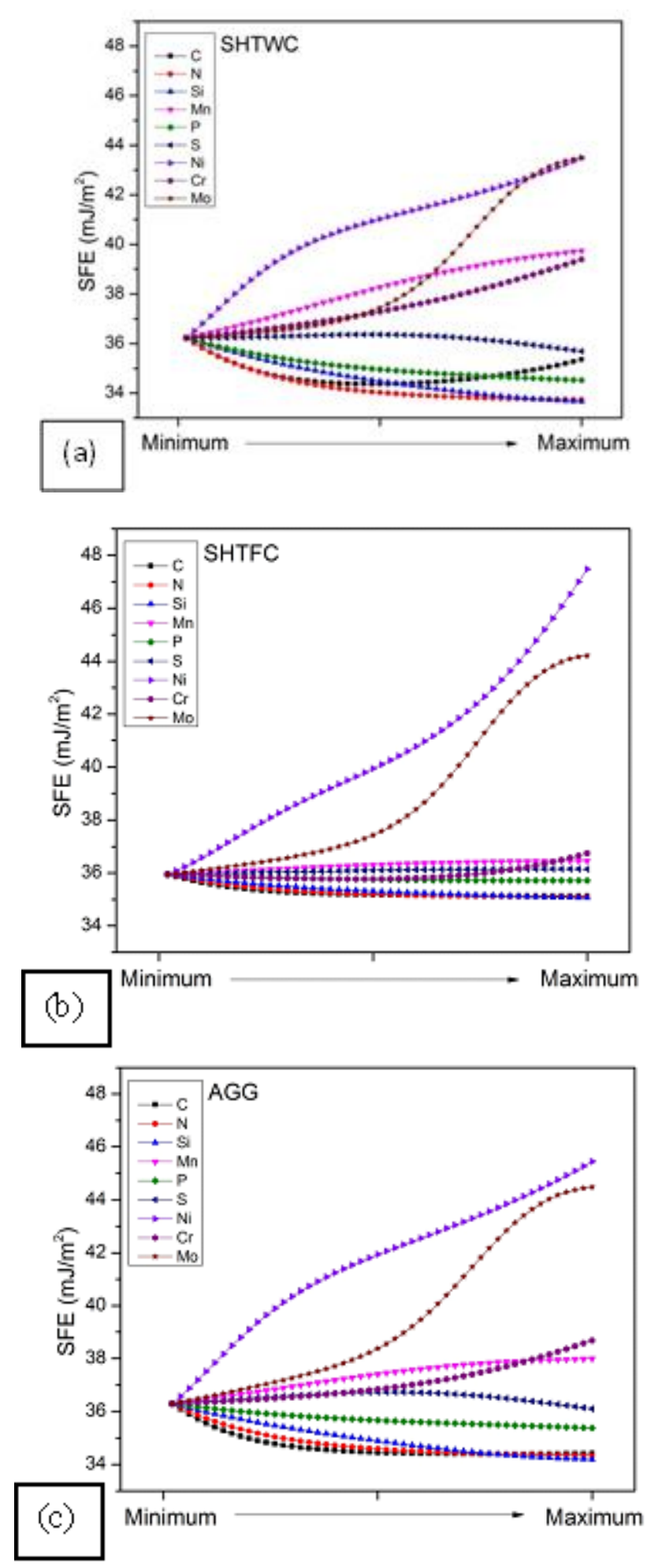

Fig. 7. Effect of all alloying elements and heat treatments on SFE. a) SHTWC. b) SHTFC. c) AGG.

\section{DISCUSSION}

The proposed model can provide a support for the design of austenitic SS, in some cases has special applications. Such is the case of corrosion behavior that is influenced by the SFE values. When Heat treatment and plastic deformation process are involved the SFE values are directly affected. Therefore it is necessary to build models considering the processes details. On the other hand, the sample characterization and preparation techniques must be considered to control the dispersion among the difference in SFE calculated. It has not been reported a specific influence of this process parameters in the simulation models developed [12], [24]-[26]. Thus, we propose the design of ANN model based on chemical composition, heat treatment and the TEM as a characterization technique, the latter due to its accuracy in obtaining the dislocation mechanism for the austenitic SS. Based on the ANN model proposed it may be established for a fully understand of the effect of the process involved in the austenitic SS. Also it can be considered as an effective general method for the calculation of SFE values, but it is required to carry out further investigations with a specific control of the parameters aforementioned. Currently, artificial intelligence programming does not turn out to be a task with the complication as years before, there are software such as MATLAB that contain interfaces to develop these methods, there are also open codes such as Google's TensorFlow, Microsoft's ONNX and ACUMOS of the Linux foundation projects that allow achieving the same purpose [48]-[50]. The prediction of SFE by ANN model is a feasible technique for its use in future research and applications for the aforementioned.

\section{CONCLUSIONS}

A feed forward backpropagation ANN was developed to predict the stacking fault energy in austenitic SS. The database used was compiled from Yonezawa's work. The efficiency obtained in the prediction of the SFE for austenitic $\mathrm{SS}$ for three types of heat treatments was $\mathrm{R}^{2}=0.99$. In addition, the proposed ANN was compared with other models, including Yonezawa's research. The present model shows an improvement in the prediction capability. It was observed that the effect of the alloy processes involved affect the SFE values. In order to obtain an effective predictive model it is necessary to build an specific database with selected chemical composition range under specific heat treatment conditions, sample preparation, plastic deformation percentage and characterization technique.

\section{ACKNOWLEDGMENTS}

A. Román Author thanks the CONACYT support (CVU: 828336) and the technical support of A. Molina Ocampo, H. H. Hinojosa Galvan, I. Puente, F. Castillo, S. Garcia and G. Aramburo.

\section{REFERENCES}

[1]Toshio, Y., Ken, S., Suguru, O., Atsushi H. The Effect of Chemical Composition and Heat Treatment Conditions on Stacking Fault Energy for Fe-Cr-Ni Austenitic Stainless Steel. Metallurgical and Materials Transactions A 44 (2013), 5884.

[2]Mumtaz, K., Takahashi, S., Echigoya, J., Kamada, Y., Zhang, L. F., Kikuchi, H., Ara, K., Sato. Magnetic measurements of martensitic transformation in austenitic stainless steel after room temperature rolling. Journal of Material Science 39 (2004) 85-97. T. Steiner y E. J. Mittemeijer. (2016). Alloying Element Nitride Development in Ferritic Fe-Based Materials Upon Nitriding: A Review. Springer link, 2091-2102.

[3]Hamilton, F. G. A., Sheyla, S. C., Pedro, L. N., Ricardo, P. S., Válder, N. F., Paulo, M. O. S., Sérgio, S. M. T. Deformation induced martensite in 
an AISI 301LN stainless steel: characterization and influence on pitting corrosion resistance Materials Research Vol. 10, No. 4,359-366, 2007.

[4]Amar, K., David C., M., Martin, C. M., John, G. S., David, K. M. Quantitative measurement of deformation-induced martensite in 304 stainless steel by X-ray diffraction. Scripta Materialia 50 (2004). 1445-1449.

[5]Peguet, L., Malki, B., Baroux, B. Influence of cold working on the pitting corrosion resistance of stainless steels. Corrosion Science 49 (2007), 1933.

[6]Byun, T.S. On the stress dependence of partial dislocation separation and deformation microstructure in austenitic stainless steels. Acta Materialia Volume 51, Issue 11, 27 June 2003, 3063-3071.

[7] Byun,T. S., Hashimoto, N., Farrell, K. Temperature dependence of strain hardening and plastic instability behaviors in austenitic stainless steels. Acta Materialia Volume 52, Issue 13, 2 August 2004, 3889-3899.

[8]Ernst, F., Cao, Y., Michal, G. M. Heuer, A.H. Carbide precipitation in austenitic stainless steel carburized at low temperature. Acta Materialia Volume 55, Issue 6, April 2007, 1895-1906.

[9]Tae-Ho, L., Eunjoo, S., Chang-Seok O., Heon-Young, H., Sung-Joon K. Correlation between stacking fault energy and deformation microstructure in high-interstitial-alloyed austenitic steels. Acta Materialia Volume 58, Issue 8, May 2010, 3173-3186.

[10] Shu-XinLi, Yan-NiHe, Shu-RongYu, Peng-YiZhang. Evaluation of the effect of grain size on chromium carbide precipitation and intergranular corrosion of 316L stainless steel. Corrosion Science Volume 66, January 2013, 211-216.

[11] Swann, P.R. Dislocation Substructure vs Transgranular Stress Corrosion Susceptibility Of Single Phase Alloys. Corrosion 1963, vol. $19,102$.

[12] Rhodes, C.G., Thompson, A.W., The composition dependence of stacking fault energy in austenitic stainless steels. Metallurgical and Materials Transactions A 8 (1977), 1901

[13] Yakubtsov, I. A., Ariapour, A., Perovic, D. D. Effect of nitrogen on stacking fault energy of f.c.c. iron-based alloys. Acta Materialia Vol. 47, No. 4, pp. 1271-1279, 1999.

[14] Ojima, M., Adachi, Y., Tomota, Y., Katada, Y., Kaneko, Y., Kuroda, K., Saka, H. Weak Beam TEM Study on Stacking Fault Energy of High Nitrogen Steels. Steel Research International 80 (2009), 477.

[15] Pierce, D., Bentley, J.,Jimenez, J., Wittig, J. Stacking fault energy measurements of $\mathrm{Fe}-\mathrm{Mn}-\mathrm{Al}-\mathrm{Si}$ austenitic twinning-induced plasticity steels. Scripta Materialia 66 (2012), 753

[16] Lee, T.H., Ha, H.Y., Hwang, B., Kim, S.J., Shin, E. Effect of Carbon Fraction on Stacking Fault Energy of Austenitic Stainless Steels. Metallurgical and Materials Transactions A, 2012, vol. 43A, 4455.

[17] Lu, J., Lars H., Erik H., Karin H. A., Mikael, G., Wei L., Levente, V., Ardeshir, G. tacking fault energies in austenitic stainless steels. Acta Materialia 111, 1 June 2016, 39.

[18] Smallman, R.E., Westmacott, K.H. Stacking faults in face-centred cubic metals and alloys. The Philosophical Magazine: A Journal of Theoretical Experimental and Applied Physics 1957, vol. 2, 669.

[19] Reed, R.P., Schramm, R.E. Relationship between stacking-fault energy and $\mathrm{x}$-ray measurements of stacking-fault probability and microstrain. Journal of Applied Phyics. 45 (1974), 4705.

[20] Huang, S.K., Wen, Y.H., Li, N., Teng, J., Ding, S., Xu, Y. G. Application of damping mechanism model and stacking fault probability in Fe-Mn alloy. Materials Characterization 59, Issue 6, June 2008, 681.

[21] Moallemi, M., Hanzaki, A.Z., Mirzaei, A. On the Stacking Fault Energy Evaluation and Deformation Mechanism of Sanicro-28 Super-Austenitic Stainless Steel. Journal of Materials Engineering and Performance 2015, vol. 24, 2335.

[22] Kang, M., Woo, W., Lee, Y.-K., Seong, B.-S. Neutron diffraction analysis of stacking fault energy in Fe-18Mn-2Al-0.6C twinning-induced plasticity steels. Materials Letters 76 (2012), 93.

[23] Schramm, R.E., Reed, R.P. Stacking fault energies of seven commercial austenitic stainless steels. Metallurgical and Materials Transactions A 6 (1975), 1345.

[24] Qi,X., An-Dong, W., Xiao-Nong, C., Xin-Min, L., Stacking fault energy of cryogenic austenitic steels. Chinese Physics 11 (2002) 596.

[25] Meric de Bellefon, G., Domain, C., van Duysen, J. C., Sridharan, K. Conference Paper . April 2016.

[26] Meric de Bellefon, G., van Duysen, J.C., Sridharan, K Composition-dependence of stacking fault energy in austenitic stainless steels through linear regression with random intercepts. Journal of Nuclear Materials 492 (2017), 227.

[27] Olson, G.B., Cohen, M. A general mechanism of martensitic nucleation: Part I. General concepts and the FCC $\rightarrow \mathrm{HCP}$ transformation. Metallurgical and Materials Transactions A 1976, vol. 7,1897

[28] Vitos, L., Nilsson, J., Johansson. B. Alloying effects on the stacking fault energy in austenitic stainless steels from first-principles theory. Acta Materialia 54 (2006), 3821

[29] Lu, S., Hu, Q.M., Johansson, B., Vitos, L. Stacking fault energies of $\mathrm{Mn}, \mathrm{Co}$ and $\mathrm{Nb}$ alloyed austenitic stainless steels. Acta Materialia 59 (2011), 5728.

[30] Geissler, D., Freudenberger, J., Kauffmann, A., Martin, S., Rafaja, D. Assessment of the thermodynamic dimension of the stacking fault energy. Philosophical Magazine 2014, vol. 94, 2967.

[31] Pierce, D., Jimenez, J., Bentley, J., Raabe, D., Oskay, C., Wittig, J. The influence of manganese content on the stacking fault and austenite/ $\varepsilon$-martensite interfacial energies in $\mathrm{Fe}-\mathrm{Mn}-(\mathrm{Al}-\mathrm{Si})$ steels investigated by experiment and theory. Acta Materialia 68 (2014), 238.

[32] Das, A. Revisiting Stacking Fault Energy of Steels. Metallurgical and Materials Transactions A 47 (2015), 748.

[33] Chiappetta, P., Colangelo, P., De Felice, P., Nardulli, G., Pasquariellod, G. Higgs search by neural networks at LHC. Physics Letters B, Volume 322, Issue 3, 17 February 1994, 219-223.

[34] Amr, R., Samy, K. H. IntechOpen Applying Artificial Neural Networks, DOI: 10.5772/51273, 2013.

[35] Saeed, S., Rouein, H., Shokoufe, T., Alimorad, R. Neural network and genetic algorithm for modeling and optimization of effective parameters on synthesized ZSM-5 particle size. Materials Letters 136 (2014), 138

[36] Yetim, A.F., Codur, M.Y., Yazici, M. Using of artificial neural network for the prediction of tribological properties of plasma nitrided 316L stainless steel. Materials Letters 158 (2015), 170.

[37] Baldi, P., Sadowski, P., Whiteson, D. Searching for exotic particles in high-energy physics with deep learning. Nature communications. doi 10.1038/ncomms5308.

[38] Jiménez-Come, M. J., Turias, I. J., Ruiz-Aguilar, J. J., Trujillo, F. Characterization of pitting corrosion of stainless steel using artificial neural networks. Journal of Materials and Corrosion 2015, 66, No. $10,1084$.

[39] Marquardt, D. W. An Algorithm for least-squares estimation of nonlinear parameters Journal of the Society for Industrial and Applied Mathematics. 1963, Vol. 11, No. 2, 431.

[40] Hagan, M.T., Menhaj, M.B. Training feedforward networks with the Marquardt algorithm. IEEE Transactions of Neural Networks Volume: 5, Issue: 6, Nov 1994, 989

[41] Martin T. H., Howard, B. D., Mark, H. B., Orlando, J. Neural network design., Chapters 10,12., ISBN $0971732116,9780971732117$.

[42] Ponce, P. Inteligencia artificial con aplicaciones a la ingeniería. Alfaomega Grupo Editor, S.A. de C.V., México., ISBN 978-607-7854-83-8.

[43] Petrov, N.Y., Yakubtsov, I.A. Thermodynamic Calculation of Stacking Fault Energy and its Effect on Fcc $\rightarrow$ Hcp Phase Transformation in Nitrogen Alloyed Stainless Steels. Materials Science Forum 1990, vol 8,889

[44] Simmons, J.W. Overview: high-nitrogen alloying of stainless steels Materials Science and Engineering A 1996, vol. 207, 159.

[45] Prokoshkina, V., Kaputkina, L. Materials Science Engineering A 2008, vols. 481-482, 762

[46] Bracke, L., Penning, J., Akdut, N. The Influence of Cr and N Additions on the Mechanical Properties of FeMnC Steels. Metallurgical and Materials Transactions A, 2007, vol. 38A, 520.

[47] Yang, J.H., Wayman, M. Self-accomodation and shape memory mechanism of $\epsilon$-martensite- - I. Experimental observations. Material Characterization, 1992, vol. 28 (1), 23.

[48] https://www.tensorflow.org/ last accessed 04/25/2018

[49] https://onnx.ai/ last accessed 04/25/2018

[50] https://www.acumos.org/ last accessed 04/25/2018 


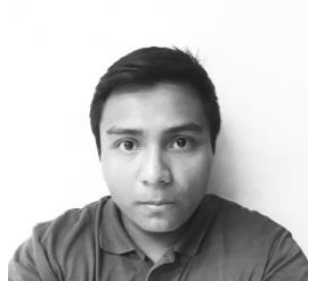

Alfonso Román Current master student at Centro de Investigación en Ingeniería y Ciencias Aplicadas, UAEM. Some areas of interest: materials science, design of prosthetic materials, application of additive technology to the biomechanical area and energy and artificial intelligence.

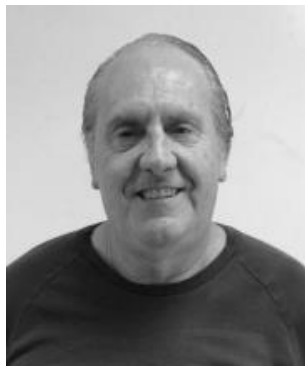

Bernardo Campilo, Dr. in metallurgical chemistry, graduated from the Universidad Nacional Autónoma de México (UNAM). Current researcher of the Instituto de Ciencias Físicas and postgraduate coordinator of the Faculty of Chemistry of the UNAM. Some areas of interest: materials science, plasma at low temperature, intermetallic materials, thermal treatments and spectroscopic techniques.

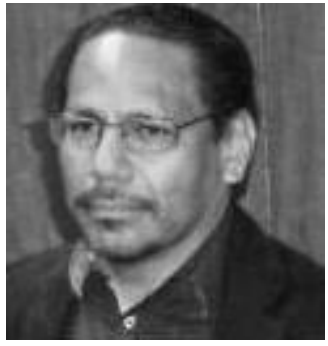

Horacio Martinez Valencia received the Ph.D. degree from Facultad de Ciencias, Universidad Nacional Autónoma de México (UNAM), México City, México, in 1987. He is currently a Researcher in the Instituto de Ciencias Fisicas, UNAM. He leads the spectroscopy laboratory of the Instituto de Ciencias Fisicas. His Research fields are basic plasma phenomena, Low temperature plasma, Plasma surface interactions, Spectroscopy of cold plasma, Plasma diagnostics and Atomic, molecular and optical physics.

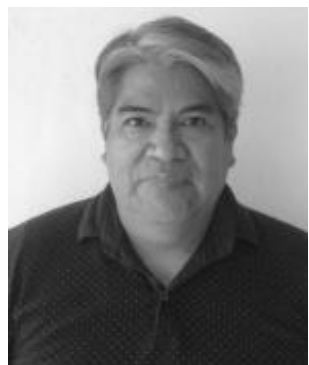

Osvaldo Flores, Dr. in Chemical Metallurgical Engineering, graduated from the Universidad Nacional Autónoma de México (UNAM) Currently in the Instituto de Ciencias Físicas and professor of postgraduate of the Faculty of Chemistry of the UNAM. Some areas of interest: materials science, plasma at low temperature, hydrogen in metals, intermetallic materials, thermal treatments, spectroscopic techniques, additive technology to the biomechanical area and energy, and design of prosthetic materials. 